\title{
Structural composition explains differences in stretchability for compression-molded arabinoxylan-based thermoplastic films
}

\author{
Parveen Kumar Deralia ${ }^{*}[\mathrm{a}]$, Amit Kumar Sonker ${ }^{[\mathrm{a}]}$, Anja Lund ${ }^{[\mathrm{a}]}$, Anette Larsson ${ }^{[\mathrm{a}]}$, Anna Ström ${ }^{[\mathrm{a}]}$ and \\ Gunnar Westman ${ }^{*[a]}$
}

[a] Department of Chemistry and Chemical Engineering

Chalmers University of Technology

Kemivägen 10, SE-41296 Gothenburg, Sweden

E-mail: deralia@chalmers.se, deralia.parveen@gmail.com and westman@chalmers.se

\begin{abstract}
Valorization of argi-waste polymers into value-added materials is essential for sustainable development of polymeric industry. Reported herein is a 1-step and 2-step strategy for fabrication of flexible and stretchable thermoplastics prepared by compression molding from two structurally different arabinoxylans (AX). The synthesis was accomplished using n-butyl glycidyl ether whose epoxide ring opened on hydroxyl group and resulted in introduction of alkoxide sidechains for the 1-step synthesis. AX was preactivated by periodate oxidation as $1^{\text {st }}$ step for the 2-step synthesis. Two structurally different AXs, i.e. wheat bran extracted arabinoxylan ( $A X_{w B}$, araf $\left./ x y l p=3 / 4\right)$ and barley husk extracted arabinoxylan $\left(A X_{B H}\right.$, araf/xylp=1/4) were used to understand the effects of the araf/xylp on thermoplastic properties because melt processability has been rare for low araf/xylp $A X s$. $A X_{B H}$-derived samples demonstrated melt compression processability. $A X_{W B}$ and $A X_{B H}$ derived thermoplastics featured dual and single glass transition $\left(T_{g}\right)$ characteristics respectively as confirmed by DSC and DMA, but $A X_{B H}$ derived thermoplastics had lower stretchability (maximum 160\%) compared to $A X_{W B}$ samples (maximum $300 \%$ ). Higher araf/xylp and thus in turn longer alkoxide side chains in $A X_{W B}$ derived thermoplastics explained differences in stretchability.
\end{abstract}

\section{Introduction}

The quest for a sustainable and bio-based economy has led to the development of technologies for converting polysaccharidebased polymers such as arabinoxylan into materials and chemicals. In this context, use of industrial polymer processing techniques, e.g. injection molding, compression molding etc. for thermoplastic materials are favored due to minimal solvent requirement, scalability, fast and efficient processing. ${ }^{1}$ Recently developed synthesis methods have shown enabling melt processability of arabinoxylans having the ratio of $\alpha$-L-arabinofuranosyl units (Araf) to $\beta$ - $(1,4)$-linked xylopyranosyl units $(X y \mid p)$ [araf/xylp] $>0.7 .^{2}$ Despite this progress, it is not known whether or not arabinoxylans having low araf/xylp ratio $(<0.5)$, e.g. barley husk arabinoxylan and xylan can be melt processed. The structural complexity of arabinoxylans and their variance both with botanical origin and isolation methods interacts with how we can process them to chemicals and materials. By studying such interactions, we may gain knowledge of not only polymer structures but also their structures-properties relationships, e.g. correlation between polymer composition and stretchability. This will help to broaden the potential application spectrum for the development of advanced materials and polymer science and will be central in enabling technology for future biorefineries. ${ }^{3}$ In this study, we isolate arabinoxylans from two major agricultural-waste streams namely wheat bran and barley husk to get two structurally different arabinoxylans (high and low araf/xylp ratio respectively) and submit them to two different chemical modification strategies with aim to enable their melt processability with the objective of identifying structure and compositional factors that may be linked primarily to stretchability and to thermomechanical properties.

Bran and husk are the external protective envelopes of wheat and barley grains. Wheat bran and barley husk are cereal/agro waste products and are valued for their renewability and abundance. These agro wastes are currently fed to livestock. These feedstocks require complete and efficient valorization approaches for conversion to chemicals and materials to compete and replace with fossilbased products. ${ }^{4}$ These are composed of mainly cellulose, arabinoxylan, lignin and other carbohydrate polymers. These natural polymers can be harnessed for materials owing to their excellent functionality. A lot of research focus has been strategized towards using cellulose and lignin for bio-based chemicals and materials.

Next to cellulose, xylan is the second most ubiquitous plant polysaccharide polymer. Cereal arabinoxylan structures are far more complex and diverse than cellulose and vary across plants. For example, the arabinoxylan of wheat bran (AXWB) often contains the high ratio of $\alpha$-L-arabinofuranosyl units (linked at C-2 and/or C-3 positions) to main-chain $\beta$ - $(1,4)$-linked xylopyranosyl subunits (araf $/ x y l p=0.7$ to 1.1) compared to the arabinoxylan of barley husk $\left(A X_{B H}\right)(\text { araf/xylp= } 0.1 \text { to } 0.4)^{2,5-10}$ This dispersity causes to loosen the intramolecular interactions in $A X_{W B}$ imparting it increased flexibility in solution and thus high-water solubility compared to $A X_{B H}{ }^{11,12}$ Taking the advantage of these inherent and diverse functionality and properties, the design and synthesis of more diverse AX-based functionalized materials with an objective of expanding application spectrum is highly needed.

AXs' hydrophilicity and brittleness are among major hurdles making them incapable to thermal processing techniques, e.g. melt compressing molding etc. It is an amorphous polymer having an extensive hydrogen-bonded network that makes it brittle and non-melt processable. Strong hydrogen-bonding manifest as a narrow window between melting/glass transition and degradation temperature. For these reasons, AXs have to submit to chemical modification to further disrupt hydrogen-bonding and to lower $T_{g}$ downshift from $T_{d}$. Chemical modifications, ${ }^{3}$ e.g. esterification, etherification, oxidation etc. of hemicelluloses are commonly used to enhance processability, properties $^{13,14}$ and functionality such as thermoplasticity, ${ }^{2,15}$ hydrophobicity ${ }^{16-19}$ and conductivity. ${ }^{20}$ Even after chemical modification hemicelluloses are only processable via organic solvents. Scaling-up via solvent processing is not feasible due 


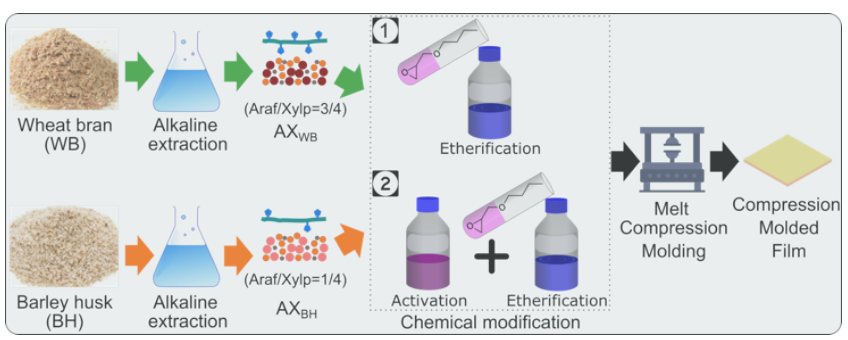

Scheme 1. Schematic diagram of the experimental steps. Wheat bran and barley husk were alkali extracted to get arabinoxylans (AX $\mathrm{X}_{\mathrm{WB}}$ and $\left.\mathrm{A} \mathrm{X}_{\mathrm{BH}}\right)$ with different structural compositions. The arabinoxylans were chemically modified via two methods and the chemically modified products were compression molded on a benchtop manual press.

to bulk requirement of solvents and time-intensive process. To harness the functionality of hemicelluloses to products, it would be advantageous if they could be processed via industrial polymer processing methods such as melt extrusion, melt compression molding. These processing methods facilitate fast processing with no or minimal solvent and low energy input. Xylans have been subjected to etherification via hydroxypropylation and with n-butyl glycidyl ether (BuGE) to produce thermoplastic xylans. ${ }^{15,21}$ Melt processing of cellulose, cellulose acetate, starch have been a success with and/or without the usage of external plasticizers. ${ }^{22-25}$ When external plasticizers are used, their migration and re-crystallization over time result in poor product performance and shorter life of thermoplastic materials; besides, these should be environmentally benign. Melt processing of hemicelluloses has not been reported until recently. 2,26

We have previously demonstrated that high araf/xylp ratio (0.8 and 1.1) AX after a one-step and two-step functionalization with BuGE can potentially be processed via polymer processing technique ${ }^{2,26}$ (and Manuscript I and II). In essence, the hydroxyl groups of AX were deprotonated into alkoxides after reacting with epoxides in these studies. We have also established the relationship between molar substitution of BuGE and obtained properties of AX-derived thermoplastics. However, thermal processability was only achieved when the Araf/Xylp ratio was 0.8 and 1.1. This remains to unravel how and why AX with particular structure and composition enables its thermal processing ability and yield flexible and stretchable thermoplastic materials. In this regard, one can have AX with different araf/xylp ratio a) either by tailoring araf/Xylp ratio enzymatically b) or by selecting two naturally available polymers with different araf/Xylp ratio. The former is a rather tedious owing to unavailability of pure enzyme components which are capable of attaching specific sites $^{27}$ and the latter offers advantages in terms of easy availability and being representatives of real industrially feedstock isolated polymers. Moreover, next challenge remains is to efficiently harness the significant untapped potentials of innate structural complexity and diversity of $\mathrm{AX}$ polymers of industrially available feedstocks to materials.

So we set out to better understand the structural, compositional and property attributes of AX with respect to the melt processability. In this work, we choose wheat bran and barley husk to extract arabinoxylans with different Araf/Xylp ratios. The primary goal is to find out whether or not possible to enable melt processability in barley husk arabinoxylan (low araf/xylp ratio). We engineer AX-derived thermoplastic materials with diverse flexibility and thermal properties by exploiting different Araf/Xylp ratios of AXs and by elongating existing groups and/or creating new alkoxide chains using BuGE. The modified AX materials are processed by the melt compression molding technique. We also attempt to identify the relationship between chemical structure and stretchability.

\section{Experimental Section}

\section{Materials and reagents}

Wheat bran and barley husk (dry matter $90 \%$ ) were provided by Lantmännen AB (Stockholm, Sweden). Arabinoxylan (AX) was extracted from wheat bran and barley husk according to the previous literature ${ }^{9}$ with slight modifications and the details are in SI. The araf/xylp ratios are $3 / 4$ and $1 / 4$ for $A X_{W B}$ and $A X_{B H}$ (Table S5). All chemicals, reagents, enzymes and solvents were purchased from Sigma-Aldrich (Schnelldorf, Germany) or Fisher Scientific (Sweden) except ethanol which was purchased from Solveco AB (Sweden). Unless otherwise stated, the chemicals were used as received. Distilled water was used throughout. Dialysis tubing (Spectra/Por $\AA$, MWCO 3500) was from Spectrum Laboratories Inc., CA, USA.

\section{Synthesis of arabinoxylan ethers and activated arabinoxylan ethers}

Scheme 1 shows a schematic presentation containing the experimental steps used in the study.

Activation of arabinoxylan. AX was activated via a successive step of periodate oxidation and reduction (Scheme 2and b) according to the reported literature. ${ }^{28,29}$ To a glass bottle with screw cap equipped with a stir bar, AX (4g dry basis, $\left.30.30 \mathrm{mmol}\right)$ and $10 \mathrm{~mL} 2-$ propanol in $165 \mathrm{~mL}$ water were added. The mixture was stirred under $\mathrm{N}_{2}$ protection at $50{ }^{\circ} \mathrm{C}$ for $1 \mathrm{~h}$ until all reagents were completely dissolved. Then sodium meta periodate $\left(0.25\right.$ mole/anhydrous sugar units dissolved in $25 \mathrm{~mL}$ water) was added. After stirring at $20^{\circ} \mathrm{C}$ for 14 in dark, $2 \mathrm{~g}$ sodium borohydride $\mathrm{NaBH}_{4}$ (reducing agent) and $0.3 \mathrm{~g}$ of sodium mono phosphate $\mathrm{NaH}_{2} \mathrm{PO}_{4}$ (used as $\mathrm{pH}$ buffer to keep the $\mathrm{pH}$ constant) in $50 \mathrm{~mL}$ water was added slowly to the reaction mixture giving $1.6 \%$ concentration (Table 1). Upon completion of reduction, $300 \mathrm{~mL}$ methanol and diethyl ether mix (2:1) was poured into the reaction content to precipitate the product. The product i.e. activated $A X(A-A X)$ was recovered after centrifugation and used without drying for etherification reaction.

Syntheses of arabinoxylan ethers (E-AX) and activated arabinoxylan ethers (E-A-AX). The activated $A X$ and neat $A X$ were etherified (Scheme $2 a$ and $b$ ) according to the reported literature ${ }^{16}$ with some changes. To a glass bottle equipped with a stir bar, the 
activated $\mathrm{AX}(\mathrm{A}-\mathrm{AX})$ or $\mathrm{AX}\left(4 \mathrm{~g}\right.$ dry basis, $30.30 \mathrm{mmol}$ ) and $60 \mathrm{~mL} \mathrm{H} \mathrm{H}_{2} \mathrm{O}$ were added, and the mixture was stirred at $50^{\circ} \mathrm{C}$ for $1 \mathrm{~h}$. The aqueous $\mathrm{NaOH}$ solution ( 3 and $5 \mathrm{~mole} \mathrm{NaOH} / \mathrm{ASU}$ in $45 \mathrm{~mL}$ - Table 1) was added after cooling the reaction to room temperature and was stirred at room temperature $\left(20^{\circ} \mathrm{C}\right)$ for additional $1 \mathrm{~h}$. The etherification reaction was carried out after adding 3 and $5 \mathrm{~mole}$ of $\mathrm{n}-$ butyl glycidyl ether/ASU dropwise over a period of $30 \mathrm{~min}$ at $45^{\circ} \mathrm{C}$ for $16 \mathrm{~h}$ (Table 1). Then the mixture was cooled and neutralized to $\mathrm{pH} 7.0$ with $2 \mathrm{M} \mathrm{CH}_{3} \mathrm{COOH}$. $150 \mathrm{~mL}$ methanol and diethyl ether mix (1:0.7) was added to the reaction to precipitate the product. The product was recovered after centrifugation and dried under vacuum at room temperature for $14 \mathrm{~h}$.

\section{Compression molding and specimen preparation}

The synthesized products were cut into small pieces to get homogenous melt and placed in either a $80 \times 80 \times 0.5$ or a $50 \times 50 \times 0.5$ $\mathrm{mm}(\mathrm{L} \times \mathrm{W} \times \mathrm{T})$ steel frame covered with transparent heat resistant plastic sheets as release surface and pressed between two flat hot platens at $150^{\circ} \mathrm{C}$ without compression in a manual bench-top press for $3 \mathrm{~min}$ for melting. Afterwards the simple melt was compressed molded in another manual bench-top press under $50 \mathrm{KPa}$ pressure at $140^{\circ} \mathrm{C}$ for $3 \mathrm{~min}$. The molded film was cooled to room temperature in ambient conditions and was removed from the frame. $A X_{W B}$ and $A X_{B H}$ films were prepared by solution casting because they were not compression moldable. The samples were dissolved either in $\mathrm{H}_{2} \mathrm{O}$ at $20 \mathrm{~g} / \mathrm{L}$ and stirred at $50{ }^{\circ} \mathrm{C}$ for $1 \mathrm{~h}$. The solution was poured into petri dish after cooling and dried at room temperature. Rectangular specimens with gauge dimensions of $20 \mathrm{~mm}$ length, $5.6 \mathrm{~mm}$ width and $0.4 \mathrm{~mm}$ thickness $(0.1 \mathrm{~mm}$ thickness for solution cast film) were cut for tensile testing. Rectangular specimens with dimensions of $30 \mathrm{~mm}$ length and $6 \mathrm{~mm}$ width and either of $0.4 \mathrm{~mm}$ thickness $(0.1 \mathrm{~mm}$ thickness for solution-cast films) were cut for DMA.

Table 1. Codes and syntheses parameters and characterizations of samples

\begin{tabular}{|c|c|c|c|c|c|}
\hline \multirow{2}{*}{$\sum_{\tilde{W}}^{\frac{\sigma}{ \pm}}$} & \multirow{2}{*}{ Sample ID ${ }^{[b]}$} & \multicolumn{3}{|c|}{$\begin{array}{l}\text { Activation via successive oxidation } \\
\text { and reduction }\end{array}$} & \multirow{2}{*}{$\begin{array}{c}\text { Etherification }^{[f]} \\
\text { Mole of } \\
\mathrm{NaOH} \text { and } \\
\text { BuGE/ASU }\end{array}$} \\
\hline & & $\begin{array}{l}\text { Mole of } \\
\text { Pl/ASU[c] }\end{array}$ & $\begin{array}{c}\text { Oxidation } \\
\text { level } 1^{[\mathrm{d}]} \\
\%\end{array}$ & $\begin{array}{c}\text { Oxidation } \\
\text { level } 2^{[\mathrm{e}]} \\
\%\end{array}$ & \\
\hline 1 & $E_{3.0}-A X_{W B}$ & - & - & - & 3 \\
\hline 2 & $E_{5.0}-A X_{W B}$ & - & - & - & 5 \\
\hline 3 & $E_{3.0}-A_{X_{B H}}$ & - & - & - & 3 \\
\hline 4 & $\mathrm{E}_{5.0}-\mathrm{A} \mathrm{X}_{\mathrm{BH}}$ & - & - & - & 5 \\
\hline 5 & $E_{3.0}-A-A X_{W B}$ & 0.25 & 19 & 24 & 3 \\
\hline 6 & $E_{5.0}-A-A X_{W B}$ & 0.25 & 19 & 24 & 5 \\
\hline 7 & $E_{3.0}-A-A X_{B H}$ & 0.25 & 15 & 28 & 3 \\
\hline 8 & $\mathrm{E}_{5.0}-\mathrm{A}-\mathrm{A} \mathrm{X}_{\mathrm{BH}}$ & 0.25 & 15 & 28 & 5 \\
\hline
\end{tabular}

[a] Entry 1-4 and 5-8 are synthesized without and with activation respectively. [b] $E_{x}-A X_{y}$ (entry 1-4) and $E_{x}-A-A X_{y}$ (entry 5-8)- $x$ denotes number of moles of BuGE, $y$ denotes origin of $A X$ and $A$ stands for activated $A X$. [c] mole equivalence of periodate (PI) per anhydrous sugar (pentose and hexose) unit (ASU), reduction reaction's parameters were similar for all reactions. [d] UV-Vis determined oxidation level. [e] oxidation level based on sugar content reduction after activation. [f] mole equivalence of $\mathrm{NaOH}$ and n-butyl glycidyl ether (BuGE) per anhydrous sugar unit (ASU) were similar.

\section{Uniaxial tensile testing}

Specimens were tested on a universal testing machine Instron 5565A (Norwood, MA, USA), equipped with a load cell of $100 \mathrm{~N}$ at $30 \mathrm{~mm} \mathrm{~min}-1$ crosshead speed at room temperature. They were air-dried and were kept at $23{ }^{\circ} \mathrm{C}$ and $50 \% \mathrm{RH}$ for $24 \mathrm{~h}$ until measurement. Results reported are the average of at least five test specimens. 


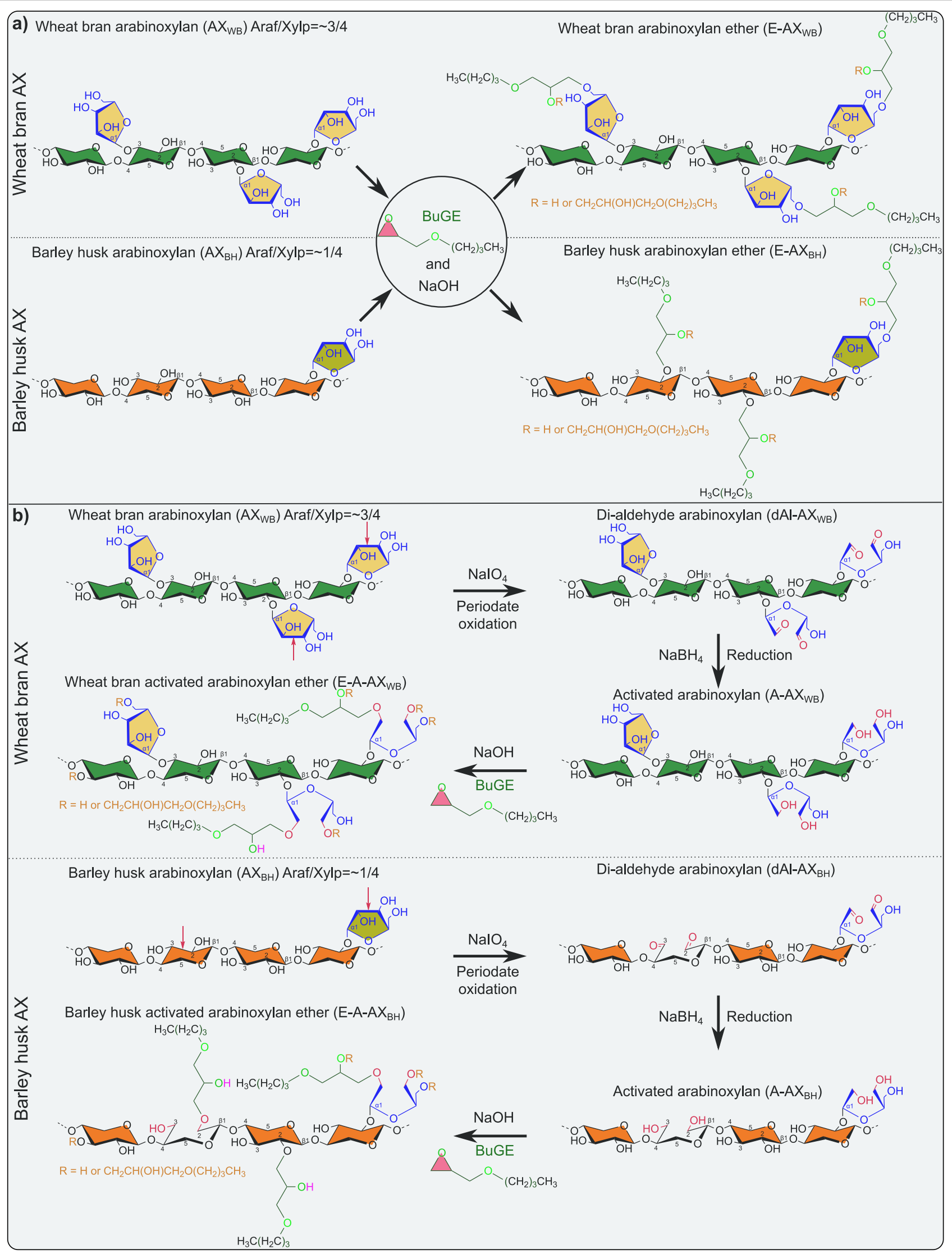

Scheme 2. Schematic presentation of the two synthesis procedures used to get thermoplastic AX. a) Arabinoxylans were directly etherified with n-butyl glycidyl ether (BuGE) to obtained $A X$ ethers in the $1^{\text {st }}$ synthesis procedure b) Arabinoxylans were first activated via successive periodate oxidation and reduction, and then etherified with BuGE to obtained activated AX ethers in the $2^{\text {nd }}$ synthesis procedure. 


\section{General characterizations}

Oxidation level. Oxidation level was quantified by periodate consumption and the sugar content reduction upon oxidation using eq. 1 and 2 given in SI.

Carbohydrate composition and NMR spectroscopy. Samples were hydrolyzed by the 2-stage sulfuric acid hydrolysis according to the NREL procedure..$^{30} 1 \mathrm{~mL}$ aliquot of the hydrolyzed sample was used for carbohydrate analysis and the rest was neutralized and freeze-dried, and then used for NMR analysis. The n-butyl glycidyl ether substitution was determined both by HPLC and NMR using eq. 3 and 5 given in SI. The solubilized monosaccharides were quantified on a Dionex ICS-4000 HPAEC system equipped with PAD (Both from Dionex, Sunnyvale, CA, USA) coupled to a Dionex CarboPac PA1 analytical column for carbohydrate analysis. 1H NMR spectra of freeze-dried monosaccharide samples (ca. $20 \mathrm{mg}$ ) dissolved in $0.7 \mathrm{~mL}$ in NMR grade D2O at $50{ }^{\circ} \mathrm{C}$ for $1 \mathrm{~h}$ were recorded on a Varian MR-400 MHz spectrometer (Agilent Technologies) at $25^{\circ} \mathrm{C}$.

Infrared. ATR-FTIR spectra were obtained on a PerkinElmer Frontier FT-IR spectrometer (Waltham, MA) equipped with an ATR accessory on room temperature dried samples successively conditioned at $23{ }^{\circ} \mathrm{C}$ and $50 \% \mathrm{RH}$ for $24 \mathrm{~h}$ between 400 and $4000 \mathrm{~cm}^{-1}$ at $2 \mathrm{~cm}^{-1}$ resolution.

Gel Permeation Chromatography (GPC). GPC was performed on a PL-GPC 50 plus integrated system equipped with RI and UV detectors (Polymer Laboratories, Varian Inc.) set at $\lambda=280 \mathrm{~nm}$ and series-coupled Polar Gel-M column and a guard column (300 $\times 7.5$ $\mathrm{mm}^{2}$ and $\left.50 \times 7.5 \mathrm{~mm}^{2}, 8 \mu \mathrm{m}\right)$ using DMSO/LiBr $(10 \mathrm{mM})$ as eluent $(0.5 \mathrm{~mL} / \mathrm{min})$. Samples were dissolved in the eluent $(2 \mathrm{mg} / \mathrm{mL})$ and filtered through syringe filters $(0.2 \mu \mathrm{m})$. Molecular weights were calculated based on the retention time of Pullulan standards (180$708000 \mathrm{Da})$.

\section{Thermal analysis}

Differential scanning calorimetry. Calorimetric analysis was performed on a Mettler Toledo DSC2 calorimeter equipped with a HSS7 sensor and a TC-125MT intercooler under nitrogen flow of $50 \mathrm{~mL} \mathrm{~min}{ }^{-1}$. Approximately $5 \mathrm{mg}$ of each was placed in $40 \mu \mathrm{l}$ aluminum pans. A heating/cooling/heating procedure was applied over a temperature range from 30 to $250^{\circ} \mathrm{C}$ and -100 to $230{ }^{\circ} \mathrm{C}$ for neat $A X$ and $A-A X$, and $E-A X$ and $E-A-A X$ samples respectively. All heating and cooling rates were $10^{\circ} \mathrm{C} \mathrm{min}^{-1}$. Two samples of each material were analyzed and $T_{g}$ was taken as the inflection point of endotherm transition in the second heating cycle. Representative DSC heating-cooling-heating cycle curves and endothermic transition highlighted second heating curves are shown in Fig. S7-S12.

Thermogravimetric analysis (TGA). TGA was performed on a TGA/DSC 3+ Star System (Mettler Toledo, Columbus, OH, USA). Samples of about $5 \mathrm{mg}$ were heated from 20 to $500^{\circ} \mathrm{C}$ at a ramp rate of $5^{\circ} \mathrm{C} \mathrm{min}$ minder a $_{2}$ flow $(50 \mathrm{~mL} / \mathrm{min})$.

Dynamic mechanical analysis (DMA). DMA was performed on a Q800 DMA (TA Instruments) in tension mode. The samples were scanned a heating rate of $3^{\circ} \mathrm{C} / \mathrm{min}$ and a frequency of $1 \mathrm{~Hz}$ with $0.02 \%$ strain.

\section{Results and Discussion}

\section{Synthesis of arabinoxylan ethers and activated arabinoxylan ethers}

A series of $A X$ ethers and activated $A X$ ethers were successfully synthesized from wheat bran $A X\left(A X_{W B}\right)$ and barley husk $A X\left(A X_{B H}\right)$ with 3 and 5 moles of BuGE (Scheme 2, reaction parameters in Table 1). Appearance of the peaks at $3000-2850 \mathrm{~cm}^{-1}(\mathrm{C}-\mathrm{H} \mathrm{stretching}$ ), $1500-1350 \mathrm{~cm}^{-1}\left(\mathrm{C}-\mathrm{H}\right.$ bending), and $740 \mathrm{~cm}^{-1}\left(\mathrm{CH}_{2} \text { rocking }\right)^{31,32}$ confirms the formation of ether linkage between hydroxyl group of the polymer and epoxide ring of BuGE (Figure 1a and b). The peak at $\sim 3300 \mathrm{~cm}^{-1}(\mathrm{O}-\mathrm{H}$ stretching) shifts slightly towards high wavenumber indicating the loosening of hydrogen-bonding in the E-AX and E-A-AX. The molar substitution (MS) and intact carbohydrate substitution (ICS) data further support the successful introduction of BuGE in the polymers (Figure 1c and Table S6) because the substitution increases with an increase in BuGE moles. The IR and MS results are in agreement with previously reported results. ${ }^{2,26}$

Substitution on arabinosyl units on side chains are favored to xylosyl units in polymer backbone as the intact arabinose substitutions (IAS) are higher than intact xylose substitutions (IXS) (Table S5). For example, the intact arabinose substitutions (IAS=0.68 and IAS= 0.78 ) on $E_{3.0} A X_{W B}$ and $E_{3.0} A X_{B H}$ are higher than intact xylose substitutions (IXS=0.51 and IXS=0.69) (Table S5). Difference in BuGE substitutions on arabinosyl and xylosyl units are higher between $A X_{B H}$ and $A X_{W B}$ derived samples when 3 moles of BuGE were used to compare to those samples when 5 moles were used (Table S5). We attribute these results to higher araf/xylp (3/4) in $A X_{W B}$ (compare to lower araf/xylp (1/4) in $\left.A X_{B H}\right)$ which hinders BuGE substitution.

The $M_{W S}$ of the $A X_{W B}$ ethers and $A X_{B H}$ ethers are lower than $A X_{W B}$ and $A X_{B H}$ (Table S6). $A X_{W B}$ has higher MW (46 kDa) than that of $A X_{B H}(21 \mathrm{kDa})$. Moreover, degradation due strong alkaline medium in the reaction and precipitation with methanol used to recover product may have caused this reduction in $M_{W}$. The reduction in $M_{W} S$ of $E-A-A X_{W B}$ and $E-A-A X_{B H}$ is even more pronounced due the degradation occurred in the activation step (successive periodate oxidation and reduction) plus precipitation step..$^{33,34}$ Note that Mws of $A-A X_{W B}$ and $A-A X_{B H}$ could not be obtained due the insolubility of theses samples in $\mathrm{DMSO} / \mathrm{LiBr}$. However, reduction in molecular weights and narrowing of molecular weight distribution (MWD) is expected. Indirect proof of these observation is present in this work because both $A X_{W B}$ and $A X_{B H}$ synthesized samples have lower molecular weights than those of their starting materials, i.e. $A X_{W B}$ and $A X_{B H}$. In addition, their MWDs are narrowed (Figure S2-S4) because the polydispersity indices are reduced (Figure 1d and Table S6). The degradation after periodate oxidation resulting in reduction in $\mathrm{Mw}^{33,35}$ and polydispersity indices ${ }^{35}$ was also reported in previous studies. 

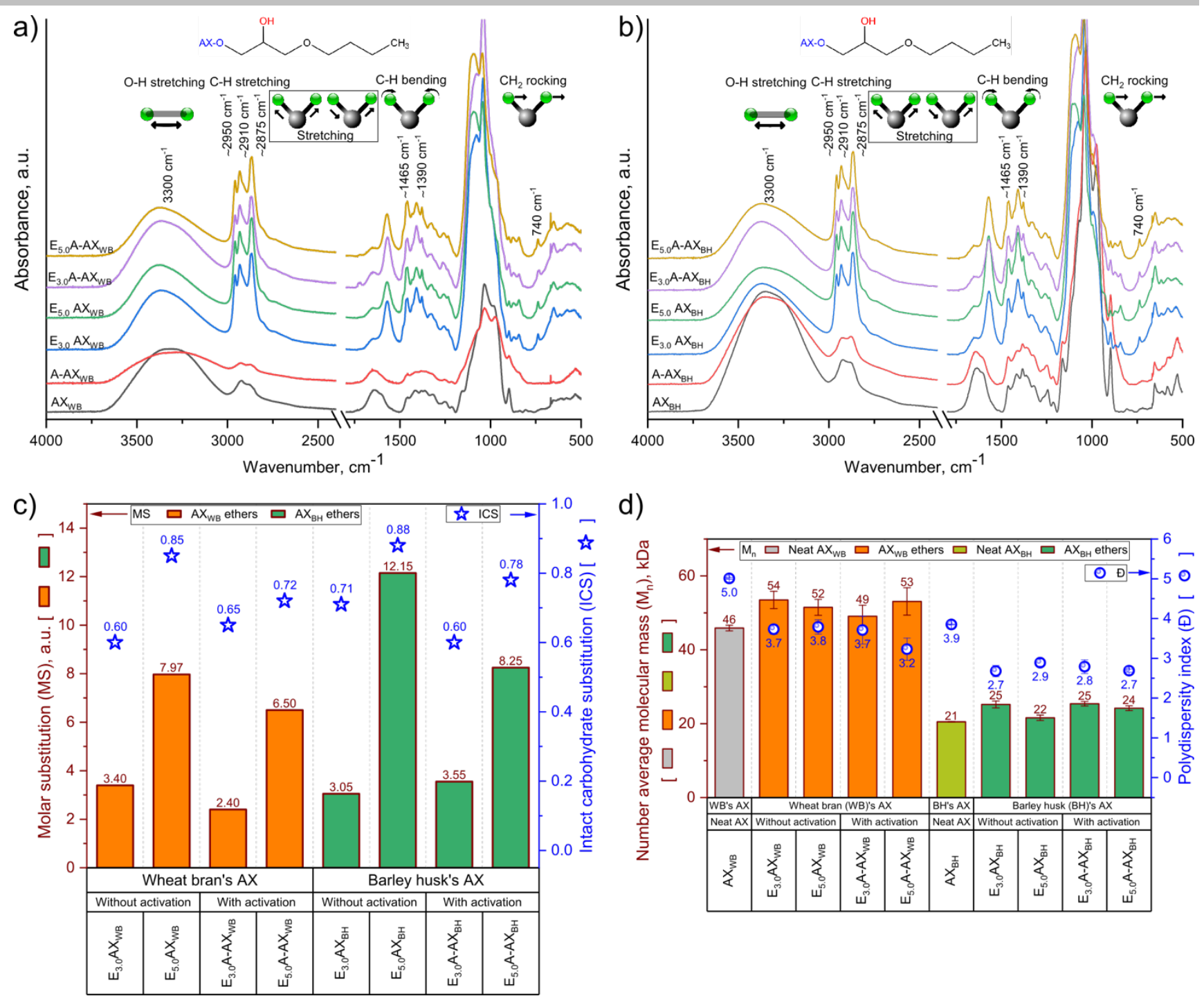

d)

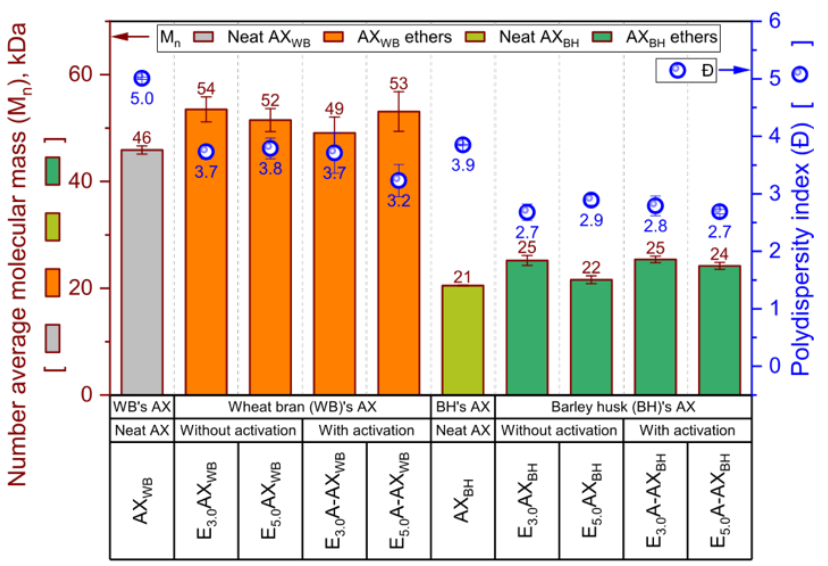

Figure 1. IR spectra of the neat $A X$, activated $A X, A X$ ether and activated $A X$ ethers acquired from a) wheat bran arabinoxylan ( $A X$ WB), b) barley husk arabinoxylan $\left(\mathrm{AX} \mathrm{BH}_{\mathrm{B}}\right.$, c) ${ }^{1} \mathrm{H}$ determined molar substitution (MS, $\square \square$ ) and HPLC determined intact carbohydrate substitution (ICS, samples of the arabinoxylans of wheat bran and barley husk and d) Average number molecular masses ( $\square \square \square \square$ and polydispersity indices ( $\square$ ) of the samples

\section{Melt compression molding}

To find the thermal processability of the synthesized samples, we used melt compression molding (at $140{ }^{\circ} \mathrm{C}$ and $50 \mathrm{kPa}$ ) which is one the industrial polymers processing techniques. All synthesized samples could be successfully compression-molded, and the obtained films are shown in Figure $2 \mathrm{~b}$ and $\mathrm{c}$. The films were flexible and foldable (Figure $2 \mathrm{~d}$ and e). The compression moldability of $\mathrm{A} \mathrm{X}_{\mathrm{WB}}$ synthesized samples whose araf/xylp ratio is $3 / 4$ was expected (Figure $2 \mathrm{~b}$ ) and has been shown previously when araf/xylp ratios were 0.8 and $1.1{ }^{2}$ Interestedly, $A X_{B H}$ synthesized samples (araf/xylp ratio $1 / 4$ ) were also compression moldable (Figure $2 \mathrm{c}$ ). This is the first ever instance when thermal processing was enabled for such low araf/xylp (1/4) AX.

\section{Properties of AX-based thermoplastics}

Thermal properties of E-AXs and E-A-AXs. DSC analysis was used to find out endothermic transitions. The DSC data of neat AXs $\left(A X_{W B}, A X_{B H}\right)$ and $A X_{B H}$ derived thermoplastics show one glass transition (Figure 2a, Figure 3a (ii) and Figure S7-S8). The presence of dual glass transitions was recorded for $A X_{W B}$ derived thermoplastics from DSC (Figure 2a and Figure 3a (i)). These dual transitions are often evident for thermoplastic polymers suggesting phase separation and were reported for multiblock synthetic polymers, ${ }^{1,36}$ conjugated polymers, ${ }^{37}$ esterified cellulose, ${ }^{22}$ lignin based thermoplastics, ${ }^{34,38}$ thermoplastic elastomers (TPE) ${ }^{39}$ The first (lower) glass transition $\left(-75\right.$ to $-48{ }^{\circ} \mathrm{C}$ ) plausibly originated from the side chain extension by alkoxide chains in the native $\mathrm{AX}$ and activated $\mathrm{AX}$ [shadowed region annotated as $\mathrm{T}_{\mathrm{g}} 1$ in Figure 3a (i) and (ii)]. The second (upper) glass transition (153 to $173{ }^{\circ} \mathrm{C}$ ) can be attributed to the xylan backbone $A X_{W B}$ derived thermoplastics [shadowed region annotated as $T_{g} 2$ in Figure $3 a$ (i)]. Contrarily the $A X_{B H}$ derived thermoplastics did not show the second glass transition $\left(T_{g} 2\right)$ because the glass transition has shifted close to or beyond degradation temperature $\left(T_{d}\right)$ as evident in Figure $3 a(i i)$. 

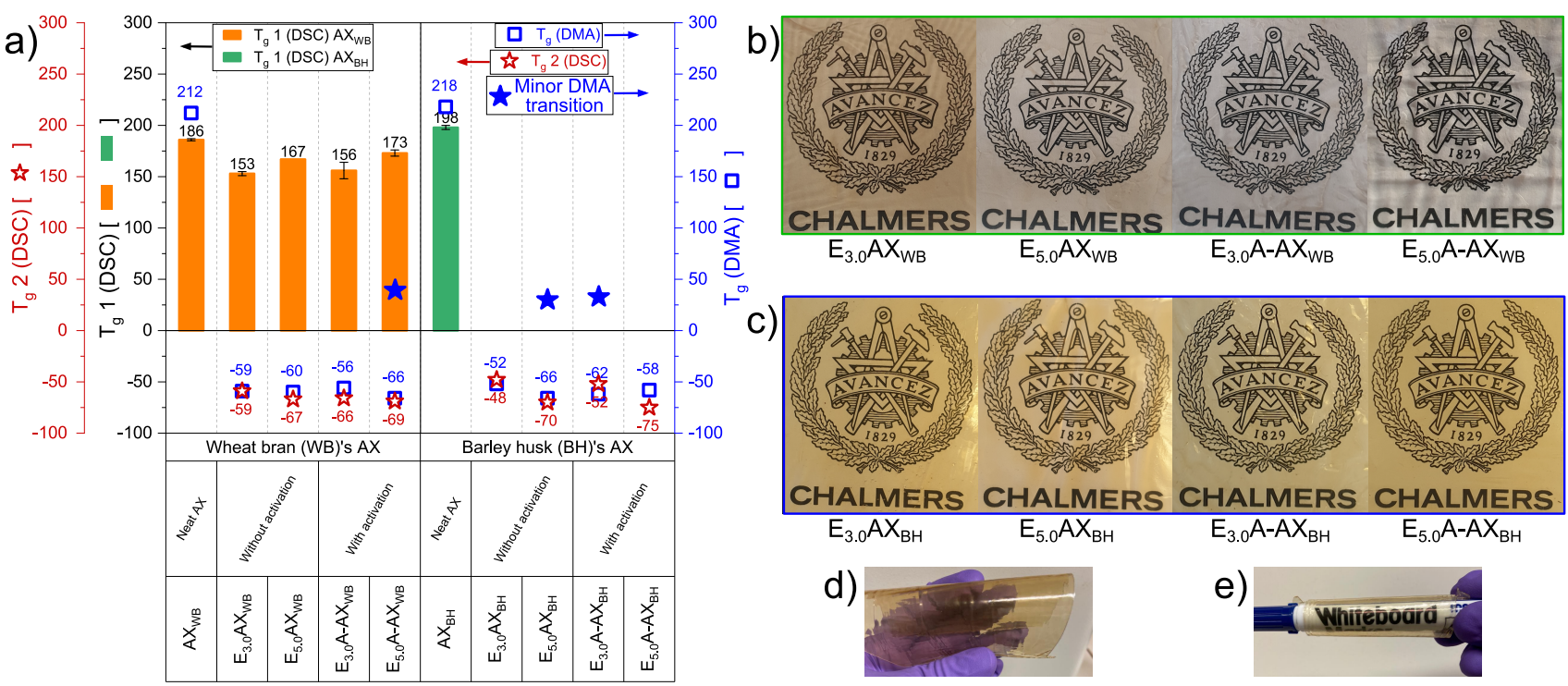

Figure 2. a) DSC (left $y$-axes, $=-$ and $\leadsto$ ) and DMA (right $y$-axis, ㅁ) determined Tgs of neat $A X$, activated AX, AX ether and activated AX samples obtained from two different types of arabinoxylans. $T_{g} 1(\square \square)$ and $T_{g} 2$ (म) denote the $T_{g} s$ determined from the above-ambient and sub-ambient endotherm transitions of the second heating DSC curves (Fig. S7-12 and Table S8). TgS (DMA, 口) were obtained from the peak of the loss modulus (E") curves (Fig. S13-17). Minor DMA transitions $(\star)$ were also observed for some samples (Fig. S15b, S16b and S17a). b) compression molded films from AXwB derived samples. c) compression molded films from $A X_{B H}$ derived samples. d) a film showing flexibility. e) a representative film folded around a marker to show foldability of the film. Note: Chalmers logo used with permission and does not claim any copyright.

Thermomechanical response of the compression molded films of $A X_{W B}$ and $A X_{B H}$ derived thermoplastics and solvent cast films of $A X_{W B}$ and $A X_{B H}$ was recorded on DMA (Figure $3 b$ and Figure S13-S17). Note that $A X_{W B}, A X_{B H}, A-A X_{W B}$ and $A-A X_{B H}$ were solvent cast because these materials are not compression moldable and A-AX films (solvent cast) were too brittle to be measured by DMA. The $T_{g} S$ obtained from loss modulus peaks are shown in Figure 2a and Table S8. $T_{g}$ annotated storage modulus, loss modulus and tan $\delta$ curves are shown in Figure S13-S17. DMA confirmed the presence of first glass transition in AXwB derived thermoplastics [Figure 2a , shadowed part in Figure 3b ii, iii, v, vi (representative DMA curves) and Fig. S14-17].

Table 2. Tensile testing and TGA results obtained for neat $A X$, activated $A X, A X_{W B}$ and $A X_{B H}$ synthesized samples

\begin{tabular}{|c|c|c|c|c|c|c|c|}
\hline \multirow{2}{*}{ Sample } & \multicolumn{3}{|c|}{ Tensile mechanical properties ${ }^{[a]}$} & \multicolumn{4}{|c|}{ TGA data ${ }^{[b]}$} \\
\hline & $\mathrm{E}, \mathrm{MPa}$ & $\sigma_{\mathrm{t}}, \mathrm{MPa}$ & $\varepsilon_{\mathrm{b}}, \%$ & $\mathrm{~T}_{\text {onset, }}{ }^{\circ} \mathrm{C}$ & $\mathrm{T}_{\text {inflection, }}{ }^{\circ} \mathrm{C}$ & $\mathrm{T}_{\text {endset, }}{ }^{\circ} \mathrm{C}$ & $\mathrm{FR}, \%$ \\
\hline$A X_{W B}$ & $2672(153)$ & $70.2(11.2)$ & $4.3(1.1)$ & $256(9)$ & $274(7)$ & $286(6)$ & $29.6(1.4)$ \\
\hline$A-A X_{W B}$ & - & - & - & $267(5)$ & $286(2)$ & $307(4)$ & $40.8(2.9)$ \\
\hline$E_{3.0}-A X_{W B}{ }^{[b]}$ & $6.9(0.6)$ & $2.7(0.5)$ & $176.7(22.5)$ & $167(18)$ & $235(3)$ & $307(4)$ & $16.1(0.2)$ \\
\hline $\mathrm{E}_{5.0}-\mathrm{AX}_{\mathrm{WB}}{ }^{[\mathrm{b}]}$ & $0.7(0.1)$ & $0.5(0.1)$ & $260.2(17.9)$ & $189(2)$ & $227(9)$ & $267(5)$ & $10.7(0.4)$ \\
\hline$E_{3.0}-A-A X_{W B}{ }^{[b]}$ & $1.4(0.2)$ & $0.9(0.3)$ & $269.7(49.2)$ & $223(1)$ & $292(1)$ & $317(1)$ & $18.1(0.5)$ \\
\hline$E_{5.0}-A-A X_{W B}{ }^{[b]}$ & $0.05(0.02)$ & $0.03(0.01)$ & $301.1(13.5)$ & $206(4)$ & $238(4)$ & $318(4)$ & $11.2(1.0)$ \\
\hline $\mathrm{AX} \mathrm{X}_{\mathrm{BH}}$ & $2455(395)$ & $39.6(5.8)$ & $2.4(0.7)$ & $252(13)$ & $274(8)$ & $286(4)$ & $27.9(1.4)$ \\
\hline $\mathrm{A}-\mathrm{A} \mathrm{X}_{\mathrm{BH}}$ & - & - & - & $263(1)$ & $282(0)$ & $296(1)$ & $32.2(0.5)$ \\
\hline $\mathrm{E}_{3.0}-\mathrm{AX}_{\mathrm{B}} \mathrm{H}^{[\mathrm{b}]}$ & $39.9(2.1)$ & $4.1(0.4)$ & $116.5(16.4)$ & $196(3)$ & $241(16)$ & $295(5)$ & $16.3(1.0)$ \\
\hline $\mathrm{E}_{5.0}-\mathrm{AX}_{\mathrm{B}} \mathrm{H}^{[\mathrm{b}]}$ & $0.9(0.2)$ & $0.3(0.06)$ & $52.1(5.7)$ & $206(4)$ & $251(1)$ & $275(1)$ & $13.7(0.7)$ \\
\hline $\mathrm{E}_{3.0}-\mathrm{A}-\mathrm{A} \mathrm{X}_{\mathrm{BH}}[\mathrm{b]}$ & $3.2(1.4)$ & $1.2(0.2)$ & $160.8(17.8)$ & $198(2)$ & $236(5)$ & $312(3)$ & $17.4(0.7)$ \\
\hline $\mathrm{E}_{5.0}-\mathrm{A}-\mathrm{A} \mathrm{X}_{\mathrm{BH}}[\mathrm{b]}$ & $0.3(0.09)$ & $0.2(0.03)$ & $140.7(15.6)$ & $179(8)$ & $266(0)$ & $315(3)$ & $12.1(0.2)$ \\
\hline
\end{tabular}

[a] data are mean $(n=5)$ values and bracketed values are standard deviations; E Young's modulus, $\sigma_{t}$ max tensile stress, $\varepsilon_{\mathbf{b}}$ tensile strain at break, - data not available

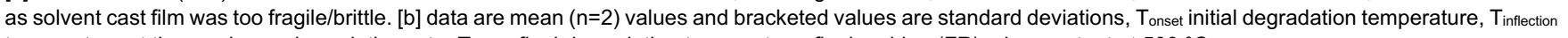

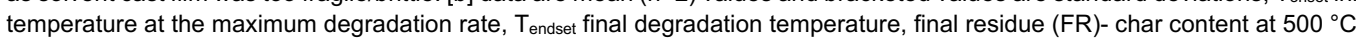



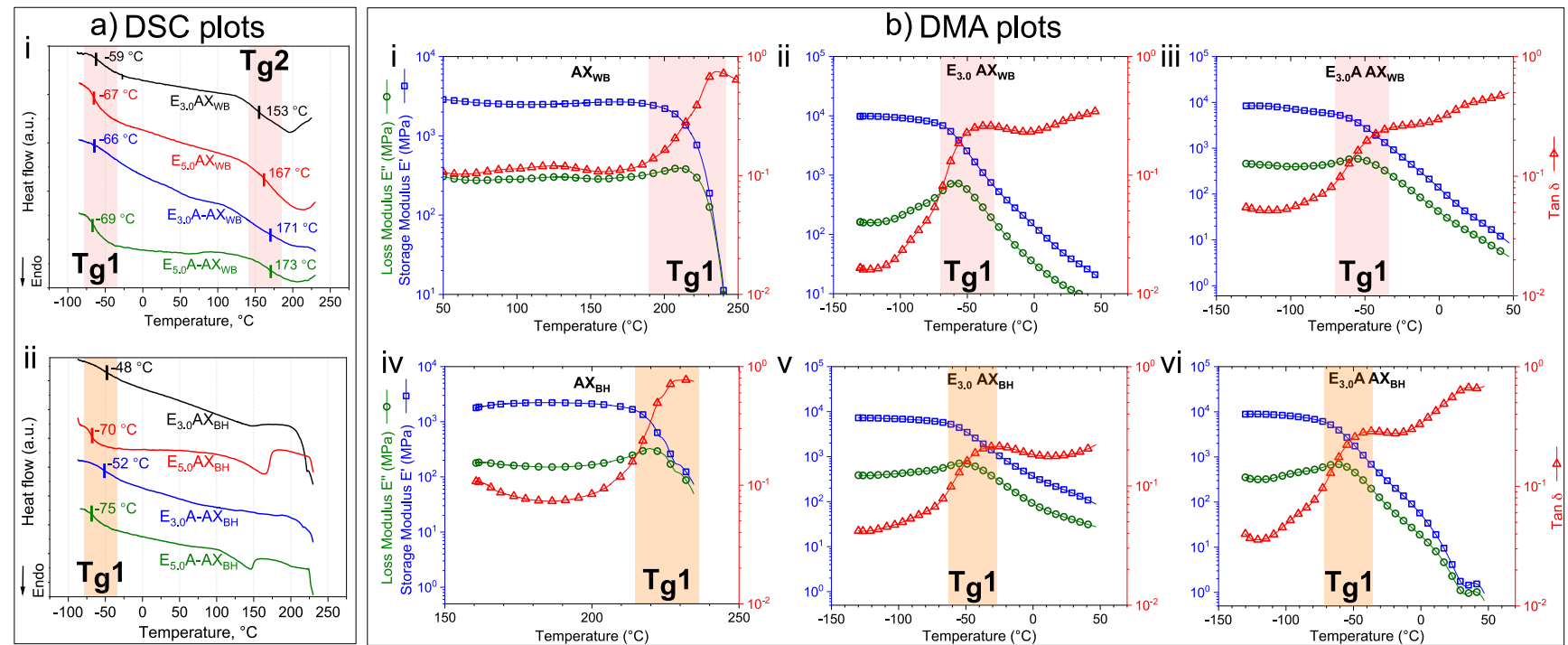

Figure 3. a) $D S C$ plots of $A X_{W B}$ and $A_{B H}$ derived thermoplastics. b) DMA of representative samples from $A X_{W B}\left(1^{\text {st }}\right.$ row) and $A X_{B H}\left(2^{\text {nd }}\right.$ row) derived thermoplastics at $3{ }^{\circ} \mathrm{C} / \mathrm{min}, 1 \mathrm{~Hz}$ frequency and $0.02 \%$ strain. DMA of i) $A X_{W B}$, ii) $E_{3.0} A X_{W B}$ iii) $E_{3.0} A-A X_{W B}$ iv) $\left.A X_{B H}, v\right) E_{3.0} A X_{B H}$, vi) $E_{3.0} A-A X_{b h}$ showing first glass transition temperature of the two glass transition temperatures $\left(T_{g}\right)$. The shadowed part highlights the $T_{g} s$ from storage modulus, loss modulus and Tan $\delta$ curves. The $2^{\text {nd }} T_{g}$ which was $>50{ }^{\circ} \mathrm{C}$ could not be recorded on DMA as these materials soften above $50{ }^{\circ} \mathrm{C}$.

The alkoxide chains formed after epoxide ring opening of BuGE and specially linked to the hydroxyl groups of arabinosyl units and ringopened arabinosyl residues makes enough long side chains (evidenced by IR data, i.e. $740 \mathrm{~cm}^{-1} \mathrm{CH}_{2}$ rocking, Figure 1a) to create a separate thermal transition corresponding to these side chains (Scheme 2 and Figure 4a). The second glass transition AX thermoplastics detected by DSC (Figure 3a) could not be recorded by DMA because the films became too soft to record thermal transition above $50^{\circ} \mathrm{C}$. Note that the differences $\left(10-20^{\circ} \mathrm{C}\right.$ ) in $\mathrm{T}_{\mathrm{g}}$ values (Figure $2 \mathrm{a}$ and Table S8) by DSC and DMA are likely due to the differences in data collection method (e.g., DMA and DSC measure dynamic and thermodynamic signal). ${ }^{38,40} \mathrm{~T}_{\mathrm{g}}$ obtained from the peak of $E^{\prime \prime}$ is lower than that obtained from tan $\delta$ peak; however, it is shown to agree better with DSC. ${ }^{40}$

Thermal stability was evaluated by TGA and Table 2 contains the TGA data. Figure S18 shows the thermograms. The initial

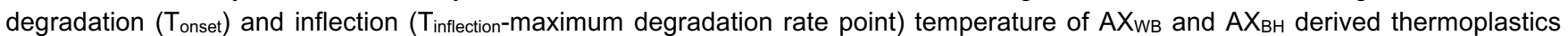
$\left(167-223^{\circ} \mathrm{C}, 227-266{ }^{\circ} \mathrm{C}\right)$ are lower $\mathrm{AX}$ and A-AX samples $\left(252-267{ }^{\circ} \mathrm{C}, 274-286{ }^{\circ} \mathrm{C}\right)$. The final residue (char content at $\left.500{ }^{\circ} \mathrm{C}\right)$ of $\mathrm{A}-$ AXs (28-30\%) are higher than AX (32-40\%). A-AXs after periodate oxidation and reduction reactions may have high amount of salts, which usually gives high amount of char yield. $A X_{W B}$ and $A X_{B H}$ derived thermoplastics have lower final residue. Overall these results are consistent with previous reports. ${ }^{2,33,41}$

Tensile mechanical properties of $A X_{W B}$ and $A X_{B H}$ thermoplastics. The $A X_{W B}$ and $A X_{B H}$ derived thermoplastics (along with $A X_{s}$ ) stress-strain behavior was determined by uniaxial tensile testing. Representative stress-strain curves are shown in Figure $4 \mathrm{c}$ and $\mathrm{d}$, and the elastic modulus $(E)$, tensile strength $\left(\sigma_{t}\right)$, and elongation at break $\left(\varepsilon_{b}\right)$ are listed in Table 2. All samples show linear stress-strain relationship. As expected, $A X_{W B}$ and $A X_{B H}$ are brittle having failure strain of $4.3\left(( \pm 1.1)\right.$ and $2.4( \pm 0.7)$. The $A X_{W B}$ and $A X_{B H}$ derived thermoplastics feature elastomeric behavior as evident from higher elongation at break and low to medium Young's modulus.

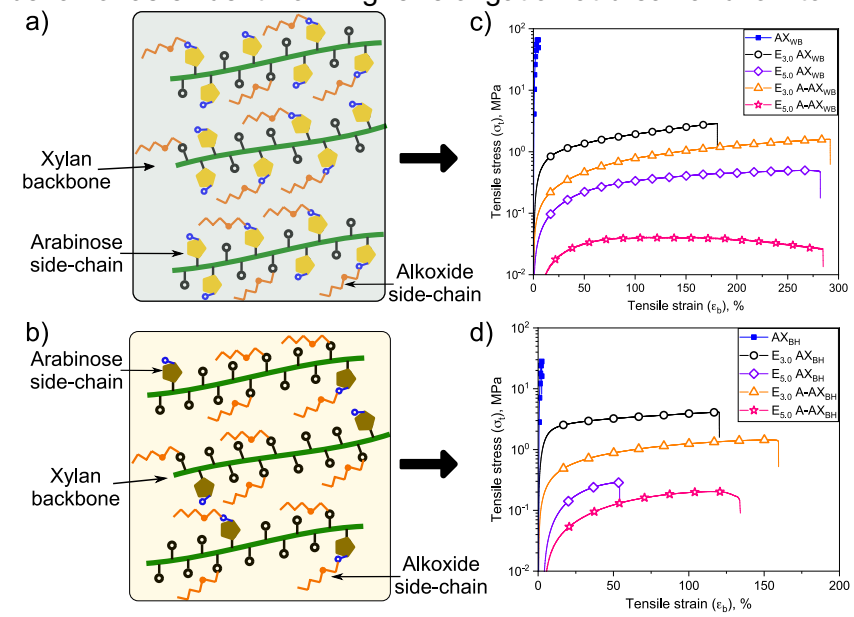

Figure 4. Proposed structure of a) $A X_{W B}$ derived thermoplastic and b) $A X_{B H}$ derived thermoplastic. Representative stress-strain curves of c) $A X_{W B}$ and $A X_{W B}$ derived samples and d) $A X_{B H}$ and $A X_{B H}$ derived samples. 
The $A X_{W B}$ derived thermoplastics have higher stretchability (177-301\%) compare to those of the $A X_{B H}$ derived thermoplastics (52$61 \%$ ) (Table 2). The elongation ranges for $A X_{W B}$ derived thermoplastics are consistent with previously reported values ${ }^{2,26}$. Higher stretchability is achieved at the expense of reduction in elastic modulus and tensile strength ${ }^{42}$ as becomes evident from the lower elastic modulus and tensile strength values of $A X_{W B}$ and $A X_{B H}$ derived thermoplastics in comparison to $A X_{W B}$ and $A X_{B H}$. Such high stretchability was not ever reported for low araf/xylp $A X$, i.e. $A X_{B H}$ derived thermoplastic processed via compression molding. However, solvent-cast films of modified reinforced (with PVA) xylan were shown to have elongation up to $133 \% .{ }^{43}$

The melt processability (Figure 2b-e) and stretchability $\left(\varepsilon_{b}\right)$ (Table 2 and Figure $4 c-d$ ) of $A X_{W B}$ and (specially of) $A X_{B H}$ derived thermoplastics are adequately promising. This encourages us to compare these with polysaccharide (cellulose acetate, ${ }^{44,45}$ starch, ${ }^{46,47}$ xylan, ${ }^{43,48}$ arabinoxylan ${ }^{2,26}$ )-based and commercial bio-based thermoplastic (polylactic acid-PLA ${ }^{49,50}$ ) processed by solvent casting and/or industrial polymer processing techniques (Figure 5). The best preference in terms of melt processing and competitive elongation at break for $\mathrm{A} \mathrm{X}_{\mathrm{BH}}$ synthesized thermoplastic is evident. This processability and elongation combination for low araf/xylp arabinoxylan has been reported in literature. Similar to our results in this work, arabinoxylan (having araf/xylp ratio between 0.8-1.1)-derived thermoplastics with such processability and elongation combination have instanced in previous reports. ${ }^{2,26}$

Cellulose acetate thermoplastics have poor elongation at break ( 35 and $2 \%$ ) but better tensile strength (29 and $26 \mathrm{MPa}$ ) compare to the thermoplastics in this study. ${ }^{44,45}$ Thermoplastic starch is both solvent and melt processable but have lower $\varepsilon_{b}$ than $A X_{B H}$ derived thermoplastic. ${ }^{46,47}$ Polylactic acid (PLA) is, although not a commodity plastic a bio-based commercial plastic. It can have similar $\varepsilon_{b}$ with superior tensile strength. ${ }^{49,50}$ Note that cellulose acetate, starch and PLA thermoplastic are semi-crystalline to highly crystalline structures. ${ }^{51}$ Xylans have never been shown melt processable ${ }^{43,48}$ but may have comparable $\varepsilon_{\mathrm{b}} .{ }^{43}$

Effect of structural composition of AX-thermoplastics on stretchability. Both 1-step and 2-step strategy enabled thermoplasticity in $A X_{W B}$ and $A X_{B H}$ synthesized samples as shown by compression molding. This suggests that the linked alkoxide side chains on hydroxyl groups of xylan backbone and/or of intact or ring-opened arabinosyl units in the side chains of AX serve as an effective internal plasticizer. These bonded alkoxide side chains are supposed to reduce the hydrogen bonding between AX molecules allowing them to slip over each other when heated above $T_{g}$. Such structures were proposed for $A X_{W B}$ and $A X_{B H}$ derived thermoplastics and depicted in Figure 4 a and b respectively.

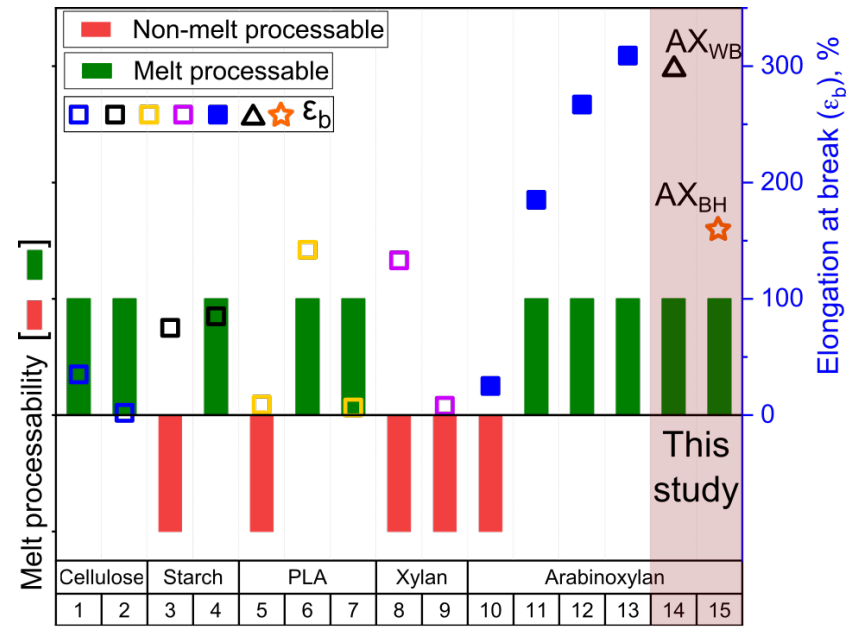

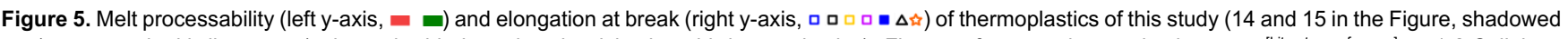

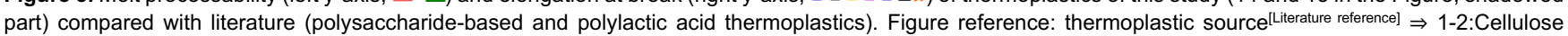
acetate, ${ }^{44,45}$ 3-4: starch, ${ }^{46,47}$ 5-7: polylactic acid-PLA, ${ }^{49,50}$ 8-9: xylan, ${ }^{43,48}$ 10-13: arabinoxylan, ${ }^{2,26}$ 14-15: $A X_{W B}$ and $A X_{B H}$ (this work). Non-melt processable denotes solvent (water or organic) processable. Araf/xylp of $A X_{W B}$ and $A X_{B H}$ are $3 / 4$ and $1 / 4$.

This is to note that higher alkoxide side chains should attach on hydroxyl groups of intact or ring-opened arabinosyl units compare to on hydroxyl groups of intact or ring-opened xylosyl units in the backbone. This is due to the easy access of hydroxyl groups of intact or ring-opened arabinosyl units being on the side chain. The araf/xylp of $A X_{W B}$ and $A X_{B H}$ are $3 / 4$ and $1 / 4$ (Table S5). Given these facts, the degree of reduction of hydrogen bonding between $A X_{W B}$ molecules will be higher than that of between $A X_{B H}$ molecules. Figure $4 C$ and $d$ and Table 2 show that the elongation of $A X_{W B}$ derived thermoplastics are higher than that of $A X_{W B}$ derived thermoplastics. These results suggest that the differences in elongation could be explained on basis of difference in araf/xylp ratio.

In this study, a successful attempt of synthesizing thermoplastics from the constituent polymer of natural and renewable resource opens up new avenues to use agri-waste for value-added materials. Our thermoplastics are partly bio-derived because arabinoxylan is bio-sourced but n-butyl glycidyl ether (BuGE) is currently a petrochemical. The renewable content can surely be increased if either BuGE can be obtained from bio-sourced routes or an already bio-sourced molecules (such as cardanol from cashew nutshell or lignin modified to increase their reactivity with arabinoxylan) can be used.

\section{Conclusion}


To summarize, we demonstrated that a 1-step and 2-step synthesis routes could be used to produce flexible and stretchable thermoplastics from low araf/xylp arabinoxylan (AX from barley husk). The synthesis strategy used only direct incorporation of BuGE or pre-activation (successive periodate oxidation and reduction) of $A X$ following incorporation of BuGE. A salient feature of these $A X_{B H}$ derived thermoplastics is that they could be processed via melt compression molding (one of the industrial polymer processing techniques) which was rare for low araf/xylp arabinoxylans. This work provides an example of converting a major constituent of agriwaste lignocellulose biomass into a value-added product.

\section{Acknowledgements}

The authors acknowledge Lantmännen for research funding (Project number 2017/H017) and thank for their kind donation of wheat bran and barley husk. We also thank Professor Hans Theliander and Professor Christian Müller for granting access to HPLC and GPC instruments and for DMA.

\section{Conflict of interest}

The authors declare no conflict of interest.

Keywords: keyword $1 \cdot$ keyword $2 \cdot$ keyword $3 \cdot$ keyword $4 \cdot$ keyword 5

\section{References}

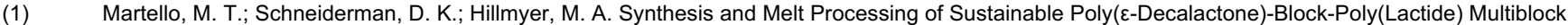
Thermoplastic Elastomers. ACS Sustain. Chem. Eng. 2014, 2 (11), 2519-2526. https://doi.org/10.1021/sc500412a.

(2) Börjesson, M.; Westman, G.; Larsson, A.; Ström, A. Thermoplastic and Flexible Films from Arabinoxylan. ACS Appl. Polym. Mater. 2019, 1 (6), 14431450. https://doi.org/10.1021/acsapm.9b00205. Ibn Yaich, A.; Edlund, U.; Albertsson, A. C. Transfer of Biomatrix/Wood Cell Interactions to Hemicellulose-Based Materials to Control Water Interaction. Chemical Reviews. American Chemical Society June 28, 2017, pp 8177-8207. https://doi.org/10.1021/acs.chemrev.6b00841.

(4) $\quad$ Apprich, S.; Tirpanalan, Ö.; Hell, J.; Reisinger, M.; Böhmdorfer, S.; Siebenhandl-Ehn, S.; Novalin, S.; Kneifel, W. Wheat Bran-Based Biorefinery 2: Valorization of Products. LWT - Food Science and Technology. 2014, pp 222-231. https://doi.org/10.1016/j.lwt.2013.12.003.

(5) Schooneveld-Bergmans, M. E. F.; Beldman, G.; Voragen, A. G. J. Structural Features of (Glucurono)Arabinoxylans Extracted from Wheat Bran by Barium Hydroxide. J. Cereal Sci. 1999, 29 (1), 63-75. https://doi.org/10.1006/jcrs.1998.0222.

(6) Izydorczyk, M. S.; Dexter, J. E. Barley $\beta$-Glucans and Arabinoxylans: Molecular Structure, Physicochemical Properties, and Uses in Food Products-a Review. Food Res. Int. 2008. https://doi.org/10.1016/j.foodres.2008.04.001.

(7) Ruthes, A. C.; Martínez-Abad, A.; Tan, H. T.; Bulone, V.; Vilaplana, F. Sequential Fractionation of Feruloylated Hemicelluloses and Oligosaccharides from Wheat Bran Using Subcritical Water and Xylanolytic Enzymes. Green Chem. 2017, 19 (8), 1919-1931. https://doi.org/10.1039/c6gc03473j.

(8) Köhnke, T.; Pujolras, C.; Roubroeks, J. P.; Gatenholm, P. The Effect of Barley Husk Arabinoxylan Adsorption on the Properties of Cellulose Fibres. Cellulose 2008, 15 (4), 537-546. https://doi.org/10.1007/s10570-008-9209-5.

(9) Börjesson, M.; Härdelin, L.; Nylander, F.; Karlsson, K.; Larsson, A.; Westman, G. Arabinoxylan and Nanocellulose from a Kilogram-Scale Extraction of Barley Husk. BioResources 2018, 13 (3), 6201-6220. https://doi.org/10.15376/biores.13.3.6201-6220.

(10) Gebruers, K.; Dornez, E.; Boros, D.; Fraś, A.; Dynkowska, W.; Bedo, Z.; Rakszegi, M.; Delcour, J. A.; Courtin, C. M. Variation in the Content of Dietary Fiber and Components Thereof in Wheats in the Healthgrain Diversity Screen. J. Agric. Food Chem. 2008, 56 (21), $9740-9749$. https://doi.org/10.1021/jf800975w

(11) Pitkänen, L.; Virkki, L.; Tenkanen, M.; Tuomainen, P. Comprehensive Multidetector HPSEC Study on Solution Properties of Cereal Arabinoxylans in Aqueous and DMSO Solutions. Biomacromolecules 2009, 10 (7), 1962-1969. https://doi.org/10.1021/bm9003767.

(12) Selig, M. J.; Thygesen, L. G.; Felby, C.; Master, E. R. Debranching of Soluble Wheat Arabinoxylan Dramatically Enhances Recalcitrant Binding to Cellulose. Biotechnol. Lett. 2015, 37 (3), 633-641. https://doi.org/10.1007/s10529-014-1705-0.

(13) Stepan, A. M.; Höije, A.; Schols, H. A.; De Waard, P.; Gatenholm, P. Arabinose Content of Arabinoxylans Contributes to Flexibility of Acetylated Arabinoxylan Films. J. Appl. Polym. Sci. 2012, 125 (3), 2348-2355. https://doi.org/10.1002/app.36458.

(14) Mikkonen, K. S.; Laine, C.; Kontro, I.; Talja, R. A.; Serimaa, R.; Tenkanen, M. Combination of Internal and External Plasticization of Hydroxypropylated Birch Xylan Tailors the Properties of Sustainable Barrier Films. Eur. Polym. J. 2015, 66, 307-318. https://doi.org/10.1016/j.eurpolymj.2015.02.034. Jain, R. K : Sjöstedt, M ; Glasser, W. G. Thermoplastic Xylan Derivatives with Propylene Oxide. Cellulose 2000. https://doi.org/10.1023/A:1009260415771.

(16) Nypelö, T.; Laine, C.; Aoki, M.; Tammelin, T.; Henniges, U. Etherification of Wood-Based Hemicelluloses for Interfacial Activity. Biomacromolecules 2016, 17 (5), 1894-1901. https://doi.org/10.1021/acs.biomac.6b00355.

(17) Fredon, E.; Granet, R.; Zerrouki, R.; Krausz, P.; Saulnier, L.; Thibault, J. F.; Rosier, J.; Petit, C. Hydrophobic Films from Maize Bran Hemicelluloses. Carbohydr. Polym. 2002, 49 (1), 1-12. https://doi.org/10.1016/S0144-8617(01)00312-5.

(18) Hartman, J.; Albertsson, A. C.; Sjöberg, J. Surface- and Bulk-Modified Galatoglucomannan Hemicellulose Films and Film Laminates for Versatile 
Oxygen Barriers. Biomacromolecules 2006, 7 (6), 1983-1989. https://doi.org/10.1021/bm060129m.

(19) Peresin, M. S.; Kammiovirta, K.; Setälä, H.; Tammelin, T. Structural Features and Water Interactions of Etherified Xylan Thin Films. J. Polym. Environ. 2012, 20 (4), 895-904. https://doi.org/10.1007/s10924-012-0469-7.

(20) Hansen, N. M. L.; Plackett, D. Sustainable Films and Coatings from Hemicelluloses: A Review. Biomacromolecules. 2008 , pp $1493-1505$. https://doi.org/10.1021/bm800053z.

(21) Laine, C.; Harlin, A.; Hartman, J.; Hyvärinen, S.; Kammiovirta, K.; Krogerus, B.; Pajari, H.; Rautkoski, H.; Setälä, H.; Sievänen, J.; et al. Hydroxyalkylated Xylans - Their Synthesis and Application in Coatings for Packaging and Paper. Ind. Crops Prod. 2013, 44, 692-704. https://doi.org/10.1016/j.indcrop.2012.08.033.

(22) Chen, Z.; Zhang, J. J.; Xiao, P.; Tian, W.; Zhang, J. J. Novel Thermoplastic Cellulose Esters Containing Bulky Moieties and Soft Segments. ACS Sustain. Chem. Eng. 2018, 6 (4), 4931-4939. https://doi.org/10.1021/acssuschemeng.7b04466.

(23) Zepnik, S.; Kabasci, S.; Kopitzky, R.; Radusch, H. J.; Wodke, T. Extensional Flow Properties of Externally Plasticized Cellulose Acetate: Influence of Plasticizer Content. Polymers (Basel). 2013, 5 (3), 873-889. https://doi.org/10.3390/polym5030873.

(24) Averous, L.; Pollet, E. Nanobiocomposites Based on Plasticized Starch. In Starch Polymers: From Genetic Engineering to Green Applications; 2014; pp 211-239. https://doi.org/10.1016/B978-0-444-53730-0.00028-2.

(25) Mathew, A. P.; Dufresne, A. Morphological Investigation of Nanocomposites from Sorbitol Plasticized Starch and Tunicin Whiskers. Biomacromolecules 2002. https://doi.org/10.1021/bm0101769.

(26) Börjesson, M.; Larsson, A.; Westman, G.; Ström, A. A Process for Preparing Modified Hemicellulose. WO-2019081677-A1, 2019.

(27) Sheldon, R. A.; Brady, D. The Limits to Biocatalysis: Pushing the Envelope. Chem. Commun. 2018, 54 (48), $6088-6104$. https://doi.org/10.1039/c8cc02463d.

(28) Siller, M.; Amer, H.; Bacher, M.; Roggenstein, W.; Rosenau, T.; Potthast, A. Effects of Periodate Oxidation on Cellulose Polymorphs. Cellulose 2015, 22 (4), 2245-2261. https://doi.org/10.1007/s10570-015-0648-5.

(29) Amer, H.; Nypelö, T.; Sulaeva, I.; Bacher, M.; Henniges, U.; Potthast, A.; Rosenau, T. Synthesis and Characterization of Periodate-Oxidized Polysaccharides: Dialdehyde Xylan (DAX). Biomacromolecules 2016, 17 (9), 2972-2980. https://doi.org/10.1021/acs.biomac.6b00777.

(30) Sluiter, A.; Hames, B.; Ruiz, R.; Scarlata, C.; Sluiter, J.; Templeton, D. Determination of Structural Carbohydrates and Lignin in Biomass Determination of Structural Carbohydrates and Lignin in Biomass. Natl. Renew. Energy Lab. 2010, 2011 (June). https://doi.org/NREL/TP-510-42618.

(31) Coates, J. Interpretation of Infrared Spectra, A Practical Approach. In Encyclopedia of Analytical Chemistry; 2006. https://doi.org/10.1002/9780470027318.a5606.

(32) Wang, J.; Somasundaran, P. Mechanisms of Ethyl(Hydroxyethyl) Cellulose-Solid Interaction: Influence of Hydrophobic Modification. J. Colloid Interface Sci. 2006. https://doi.org/10.1016/j.jcis.2005.06.072.

(33) Börjesson, M.; Larsson, A.; Westman, G.; Ström, A. Periodate Oxidation of Xylan-Based Hemicelluloses and Its Effect on Their Thermal Properties. Carbohydr. Polym. 2018, 202, 280-287. https://doi.org/10.1016/j.carbpol.2018.08.110.

(34) Saito, T.; Brown, R. H.; Hunt, M. A.; Pickel, D. L.; Pickel, J. M.; Messman, J. M.; Baker, F. S.; Keller, M.; Naskar, A. K. Turning Renewable Resources into Value-Added Polymer: Development of Lignin-Based Thermoplastic. Green Chem. 2012, 14 (12), 3295-3303. https://doi.org/10.1039/c2gc35933b.

(35) Muhammad, M.; Willems, C.; Rodríguez-Fernández, J.; Gallego-Ferrer, G.; Groth, T. Synthesis and Characterization of Oxidized Polysaccharides for In Situ Forming Hydrogels. Biomolecules 2020, 10 (8), 1185. https://doi.org/10.3390/biom10081185.

(36) Zhang, J.; Deubler, R.; Hartlieb, M.; Martin, L.; Tanaka, J.; Patyukova, E.; Topham, P. D.; Schacher, F. H.; Perrier, S. Evolution of Microphase Separation with Variations of Segments of Sequence-Controlled Multiblock Copolymers. Macromolecules 2017, 50 (18), $7380-7387$. https://doi.org/10.1021/acs.macromol.7b01831.

(37) Sharma, A.; Pan, X.; Bjuggren, J. M.; Gedefaw, D.; Xu, X.; Kroon, R.; Wang, E.; Campbell, J. A.; Lewis, D. A.; Andersson, M. R. Probing the Relationship between Molecular Structures, Thermal Transitions, and Morphology in Polymer Semiconductors Using a Woven Glass-Mesh-Based DMTA Technique. Chem. Mater. 2019, 31 (17), 6740-6749. https://doi.org/10.1021/acs.chemmater.9b01213.

(38) Saito, T.; Perkins, J. H.; Jackson, D. C.; Trammel, N. E.; Hunt, M. A.; Naskar, A. K. Development of Lignin-Based Polyurethane Thermoplastics. RSC Adv. 2013, 3 (44), 21832-21840. https://doi.org/10.1039/c3ra44794d.

(39) Gregory, G. L.; Sulley, G. S.; Carrodeguas, L. P.; Chen, T. T. D.; Santmarti, A.; Terrill, N. J.; Lee, K. Y.; Williams, C. K. Triblock Polyester Thermoplastic Elastomers with Semi-Aromatic Polymer End Blocks by Ring-Opening Copolymerization. Chem. Sci. 2020, 11 (25), 6567-6581. https://doi.org/10.1039/d0sc00463d.

(40) Cao, Z.; Galuska, L.; Qian, Z.; Zhang, S.; Huang, L.; Prine, N.; Li, T.; He, Y.; Hong, K.; Gu, X. The Effect of Side-Chain Branch Position on the Thermal Properties of Poly(3-Alkylthiophenes). Polym. Chem. 2020, 11 (2), 517-526. https://doi.org/10.1039/c9py01026b.

(41) Fukuzumi, H.; Saito, T.; Iwata, T.; Kumamoto, Y.; Isogai, A. Transparent and High Gas Barrier Films of Cellulose Nanofibers Prepared by TEMPOMediated Oxidation. Biomacromolecules 2009, 10 (1), 162-165. https://doi.org/10.1021/bm801065u.

(42) Ritchie, R. O. The Conflicts between Strength and Toughness. Nat. Mater. 2011. https://doi.org/10.1038/nmat3115.

(43) Zhang, X.; Liu, C.; Zhang, A.; Sun, R. Synergistic Effects of Graft Polymerization and Polymer Blending on the Flexibility of Xylan-Based Films. Carbohydr. Polym. 2018, 181, 1128-1135. https://doi.org/10.1016/j.carbpol.2017.11.025.

(44) Fridman, O. A.; Sorokina, A. V. Criteria of Efficiency of Cellulose Acetate Plasticization. Polym. Sci. - Ser. B 2006, 48 (5), $233-236$. https://doi.org/10.1134/S1560090406090028.

(45) Cheng, G.; Wang, T.; Zhao, Q.; Ma, X.; Zhang, L. Preparation of Cellulose Acetate Butyrate and Poly(Ethylene Glycol) Copolymer to Blend with Poly(3Hydroxybutyrate). J. Appl. Polym. Sci. 2006, 100 (2), 1471-1478. https://doi.org/10.1002/app.23135.

(46) Huang, L.; Xu, H.; Zhao, H.; Xu, M.; Qi, M.; Yi, T.; An, S.; Zhang, X.; Li, C.; Huang, C.; et al. Properties of Thermoplastic Starch Films Reinforced with Modified Cellulose Nanocrystals Obtained from Cassava Residues. New J. Chem. 2019, 43 (37), 14883-14891. https://doi.org/10.1039/c9nj02623a. 
(47) Salaberria, A. M.; Labidi, J.; Fernandes, S. C. M. Chitin Nanocrystals and Nanofibers as Nano-Sized Fillers into Thermoplastic Starch-Based Biocomposites Processed by Melt-Mixing. Chem. Eng. J. 2014, 256, 356-364. https://doi.org/10.1016/j.cej.2014.07.009.

(48) Alekhina, M.; Mikkonen, K. S.; Alén, R.; Tenkanen, M.; Sixta, H. Carboxymethylation of Alkali Extracted Xylan for Preparation of Bio-Based Packaging Films. Carbohydr. Polym. 2014, 100, 89-96. https://doi.org/10.1016/j.carbpol.2013.03.048.

(49) Martin, O.; Avérous, L. Poly(Lactic Acid): Plasticization and Properties of Biodegradable Multiphase Systems. Polymer (Guildf). 2001, 42 (14), 62096219. https://doi.org/10.1016/S0032-3861(01)00086-6.

(50) Xu, Y. Q.; Qu, J. P. Mechanical and Rheological Properties of Epoxidized Soybean Oil Plasticized Poly(Lactic Acid). J. Appl. Polym. Sci. 2009, 112 (6), 3185-3191. https://doi.org/10.1002/app.29797.

(51) Iji, M.; Moon, S.; Tanaka, S. Hydrophobic, Mechanical and Thermal Characteristics of Thermoplastic Cellulose Diacetate Bonded with Cardanol from Cashew Nutshell. Polym. J. 2011, 43 (8), 738-741. https://doi.org/10.1038/pj.2011.57. 


\section{Entry for the Table of Contents}

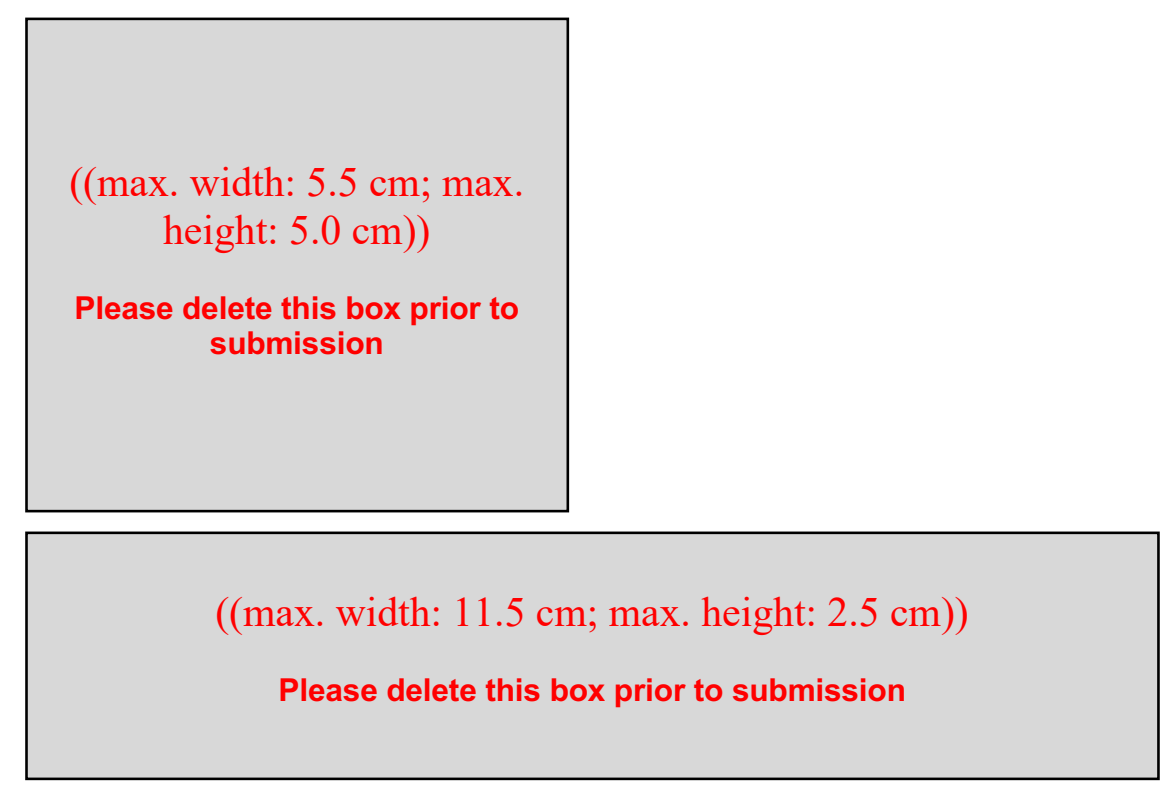

Video provides a powerful way to help you prove your point. When you click Online Video, you can paste in the embed code for the video you want to add. You can also type a keyword to search online for the video that best fits your document.

Institute and/or researcher Twitter usernames: @chalmersuniv, @Parveenderalia 